\title{
LETRAMENTOS MULTIMODAIS PARA O ENSINO DO PORTUGUÊS COMO SEGUNDA LÍNGUA PARA SURDOS
}

\author{
ALFABETIZACIÓN MULTIMODAL PARA LA ENSEÑ ANZA DEL PORTUGUÉS \\ COMO SEGUNDA LENGUA PARA LOS SORDOS
}

\author{
MULTIMODAL TEACHING OF PORTUGUESE AS A SECOND LANGUAGE FOR \\ THE DEAF
}

Yuri Miguel MACEDO ${ }^{1}$

\begin{abstract}
RESUMO: O presente artigo apresenta uma proposta pedagógica que visa à construção de um vídeo multimodal com as letras das músicas de Dorival Caymmi, envolvendo os multiletramentos (linguístico, visual, gestual, espacial e áudio) no sentido de desenvolver a capacidade comunicativa dos sujeitos surdos envolvidos no processo de ensino-aprendizagem, criando contextos de produções reais, possibilitando atividades múltiplas e, sobretudo, atividades que valorizem o princípio Bakhtiniano da interação, do dialogismo. A proposta organiza-se a partir dos procedimentos de apresentação de situações de comunicação envolvendo os gêneros discursivos multimodais considerando os alunos protagonistas do conhecimento. O projeto foi desenvolvido no Atendimento Educacional Especializado - AEE, no contexto escolar que tem por referência uma perspectiva bilíngue, onde os alunos usam a Língua Brasileira de Sinais como primeira língua (L1) e a língua portuguesa na modalidade escrita como segunda língua (L2), envolvendo as áreas de Libras e Português escrito no sentido de aproximar as crianças surdas às práticas letradas. A escolha do autor deu-se devido à comemoração do seu centenário, às suas composições que retratam e valorizam a Bahia, ao fato dos alunos serem baianos e pensando no nível de complexidade dos textos apropriados para a compreensão dos alunos surdos em questão.
\end{abstract}

PALAVRAS-CHAVE: Multiletramentos. Escola bilíngue. Língua de sinais. Língua portuguesa escrita.

RESUMEN: Este artículo presenta una propuesta pedagógica que tiene como objetivo construir un video multimodal con la letra de las canciones de Dorival Caymmi, involucrando las herramientas múltiples (lingüisticas, visuales, gestuales, espaciales y de audio) para desarrollar la capacidad comunicativa de los sordos involucrados en el proceso de enseñanzaaprendizaje creando contextos de producciones reales, permitiendo múltiples actividades y, sobre todo, actividades que valoran el principio de interacción de Bakhtin, el diálogo. La propuesta se organiza en base a los procedimientos para la presentación de situaciones de comunicación que involucran géneros discursivos multimodales considerando a los estudiantes como protagonistas del conocimiento. El proyecto se desarrolló en el Servicio Educativo Especializado - AEE, en el contexto escolar que tiene como referencia una perspectiva bilingüe, donde los estudiantes usan el lenguaje de señas brasileño como su primer idioma (L1) y el

${ }^{1}$ Universidade Federal do Sul da Bahia (UFSB), Itabuna - BA - Brasil. Mestrando no Programa de Pós-Graduação em Educação e Relações Étnico-Raciais. ORCID: http://orcid.org/0000-0003-0926-6553. E-mail: yurimacedo@id.uff.br 
portugués en forma escrita como segundo idioma (L2), involucrando las áreas de Libras y el portugués escrito para acercar a los niños sordos a las prácticas alfabetizadas. La elección del autor se debió a la celebración de su centenario, sus composiciones que retratan y valoran a Bahía, el hecho de que los estudiantes son bahianos y piensan en el nivel de complejidad de los textos apropiados para la comprensión de los estudiantes sordos en cuestión.

PALABRAS CLAVE: Alfabetización múltiple. Escuela bilingüe. Lenguaje de señas. Lengua portuguesa escrita.

ABSTRACT: This article presents a pedagogical proposal that aims to build a multimodal video with the lyrics of Dorival Caymmi's songs, involving the multiliteracy (linguistic, visual, gestural, spatial and audio) in order to develop the communicative capacity of the deaf subjects involved in the teaching-learning process creating contexts of real productions, enabling multiple activities and, above all, activities that value the Bakhtinian principle of interaction, dialogism. The proposal is organized based on the procedures for the presentation of communication situations involving multimodal discursive genres considering students as protagonists of knowledge. The project was developed in the Specialized Educational Service $A E E$, in the school context that has as a reference a bilingual perspective, where students use the Brazilian Sign Language as their first language (L1) and Portuguese in written form as a second language (L2), involving the areas of Libras and written Portuguese in order to bring deaf children closer to literate practices. The choice of the author was due to the celebration of the artist centenary, his compositions that portray and value Bahia, the fact that the students are from Bahia and thinking about the level of complexity of the texts appropriate for the understanding of the deaf students in question.

KEYWORDS: Multiliteracy. Bilingual school. Sign language. Written portuguese language.

\section{Introdução}

Uma das discussões centrais na área de educação decorre da atual política nacional que preconiza a educação inclusiva, ou seja, aquela organizada para atender a todos. Todavia, para obtenção de bons resultados educacionais, no que se refere à criança surda, suas condições linguísticas e culturais devem ser necessariamente contempladas. No entanto, não é isso que ocorre com frequência nas escolas. As crianças surdas, de forma geral, não tem tido seus direitos à educação respeitados devido às dificuldades de acesso à língua utilizada pela maioria, com isso ficam excluídas dos processos ensino-aprendizagem; como consequência, após anos de escolarização, é comum não apresentarem um domínio mínimo dos conceitos e conteúdos ministrados, necessário ao seu desenvolvimento e a sua adequada inserção social.

Partindo dos pressupostos do conceito de multiletramentos e com a necessidade de atender os alunos surdos nas suas especificidades linguísticas foi implantado o Atendimento Educacional Especializado - AEE, através da Associação Educacional Sons no Silêncio - 
AESOS, instituição conveniada à Secretaria Municipal de Educação - SMED, de acordo com o texto da política de educação especial na perspectiva inclusiva. O AEE é um serviço da educação especial que identifica, elabora e organiza recursos pedagógicos e de acessibilidade que eliminam as barreiras para a plena participação da cidadania dos alunos, considerando as especificidades dos mesmos, para promover uma prática pedagógica na perspectiva dos multiletramentos. Os professores do AEE constroem materiais didáticos, fazem adaptações de atividades dos livros didáticos, livros infantis, entre outros, e quando os conceitos são muito abstratos utilizam-se imagens, slides, texto informativo e vídeo (tradução simultânea) com legenda e outros recursos.

As dificuldades que os profissionais encontram para trabalhar com alunos surdos são: a escassez de materiais didáticos e a falta de proposta metodológica adequada, o que gerou uma inquietação em relação aos trabalhos metodológicos desenvolvidos no AEE. Percebeu-se que os vídeos multimodais, especificamente, despertam um grande interesse nos alunos surdos, que demonstraram uma melhor compreensão dos conceitos trabalhados no atendimento e superam as visões linguísticas fragmentadas.

\section{Prática Pedagógica Multiletrada para Alunos Surdos}

Conforme Fernandes (2006), as propostas de educação brasileira para surdos, historicamente, sustentaram-se nos parâmetros estabelecidos para o ensino-aprendizagem do sujeito ouvinte. O contexto educacional (da escola regular) está organizado de forma que todas as interações são realizadas pela oralidade, o que coloca os alunos surdos em extrema desvantagem nas relações instauradas na sala de aula, que são pautadas no binômio foucaultiano saber/poder, relegando-os a ocupar o eterno "lugar" do desconhecimento, do erro, da ignorância, da ineficiência, do eterno não-saber nas práticas linguísticas.

A educação dos surdos precisa fundamentar-se nos princípios legais que garantam aos surdos o direito à diferença. Refletindo sobre a inclusão no Brasil, Lacerda (2000) alerta para o fato de que o aluno surdo não compartilha uma língua com seus colegas e professores, estando em desigualdade linguística na sala de aula. A inclusão dos surdos está sendo feita sem garantir aos surdos o direito à diferença linguística e sem entender as consequências desse processo para o aluno, sem se dar conta de que os sujeitos surdos possuem uma identidade linguística e cultural que os diferencia.

As práticas de letramentos devem ser contempladas para formação de leitores sob perspectiva Bakhtiniana como "responsivo", ou seja, como alguém que adota uma postura de 
compreensão responsiva ativa: "concorda ou discorda (total ou parcialmente), completa, adapta, apronta-se para executar" (apud ROJO, 2013, p. 125) e cumpre sua função protagonista de sujeito que interage e se comunica. Tendo em vista as necessidades dos alunos surdos, as competências e habilidades almejadas no ensino-aprendizagem da educação formal tornam necessários os trabalhos com o conceito Bakhtiniano de gêneros discursivos.

É preciso considerar a especificidade do contexto linguístico das escolas inclusivas que não favorecem um vínculo comunicativo de interações linguísticas entre os alunos surdos e a comunidade escolar. As crianças surdas, ainda que estejam imersas na cultura ouvinte, não se apropriam da língua portuguesa pela interação com a família e sociedade e, na maioria das vezes, por conta de seus familiares serem ouvintes, comunicam-se por meio da língua portuguesa oral, aumentando a barreira linguística.

Nesse contexto, a maioria das crianças acessa a escola com uma linguagem construída em ambiente familiar para fins de comunicação. Conforme Karnopp e Pereira (2004), o distanciamento das práticas de leitura e escrita e a pouca familiaridade com o português resultam em alunos que sabem decodificar alguns símbolos gráficos, mas não atribuem sentido ao que leem.

Frente ao reconhecimento da Língua Brasileira de Sinais como meio legal de comunicação e expressão do cidadão surdo, Lei $\mathrm{n}^{0} 10.436$, de 24 de abril de 2002, regulamentada pelo Decreto $\mathrm{n}^{\circ} 5.626$, de 22 de dezembro de 2005, apresentamos uma proposta pedagógica: vídeo multimodal para utilizar nas escolas bilíngues para surdos. $\mathrm{O}$ artigo $2 .^{\circ}$ deste Decreto traz uma definição da pessoa surda como sendo aquela que, por ter perda auditiva, compreende e interage com o mundo por meio de experiências visuais, manifestando sua cultura principalmente pelo uso da Língua Brasileira de Sinais (BRASIL, 2002; 2005).

Segundo Rojo (2009), a participação da criança nas práticas de leitura e escrita depende do grau de letramento familiar e instituição escolar que permitirá ao sujeito construir uma relação com a escrita de prática discursiva. Dessa forma, o bilinguismo tem sido pensado como facilitador desse processo de construção do conhecimento, tanto no ambiente familiar quanto no ambiente escolar.

Para Quadros (2008), as crianças surdas e seus pais ouvintes poderiam compartilhar o bilinguismo: língua portuguesa e língua de brasileira de sinais, descobrindo as culturas e identidades que se entrecruzam. A coexistência das duas línguas na escola, como chama atenção Quadros e Schmiedt (2006), favorece o aprendizado significativo do português escrito porque permite que a criança, através de sua língua natural, dê significado e valor ao aprendizado de uma segunda língua, o que também é afirmado por Fernandes (2006). 
Segundo Soares (2008), letramento é o estado daquele que não só sabe ler e escrever, mas que também faz uso competente e frequente da leitura e escrita, e que, ao tornar-se letrado, muda seu lugar social, seu modo de viver na sociedade, sua inserção na cultura. Ampliando o conceito de letramento para crianças surdas, Quadros (2006) afirma que o processo de letramento faz sentido se significado por meio da língua de sinais brasileira, a língua usada na escola para aquisição das línguas para aprender por meio dessa língua e para aprender sobre as línguas. A língua portuguesa, portanto, será a segunda língua da criança surda, sendo significada pela criança na sua forma escrita com as suas funções sociais representadas no contexto brasileiro.

Para promover uma prática pedagógica multiletrada, oportunizando aos alunos experimentarem diversos tipos de linguagens, torna-se necessário fazer uso das tecnologias digitais e elaborar recursos midiáticos para favorecer a formação de leitores reflexivos, críticos com habilidades para fazerem novos links, tornando-se necessárias produções de mídias digitais multimodais, utilizando em suas composições os recursos oferecidos pela tecnologia, com hiperlinks, imagens, promovendo interatividade e rompendo com a linearidade dos textos.

Trabalhar com multiletramentos pode ou não envolver (normalmente envolverá) o uso de novas tecnologias da comunicação e de informação (novos letramentos), mas caracteriza-se como um trabalho que parte das culturas de referência do alunado (popular, local, de massa) e de gêneros, mídias e linguagens por eles conhecidos, para buscar um enfoque crítico, pluralista, ético e democrático - que envolva agência - de textos/discursos que ampliem o repertório cultural, na direção de outros letramentos (ROJO; MOURA, 2012, p. 8).

A partir da prática pedagógica no AEE desta escola de surdos na cidade de Salvador/Bahia, no ano de 2014, foi construído o vídeo multimodal com textos de Dorival Caymmi com alunos na faixa etária de 7 a 19 anos, com múltiplas deficiências, egressos na escola bilíngue tardiamente, tendo seu primeiro contato com a escolarização numa escola regular sem contato com a libras, com outros surdos, nem com os letramentos multimodais.

Para o desenvolvimento deste artigo, escolhemos apenas um texto de Caymmi, contudo, os demais seguiram o mesmo modelo. A seguir serão descritas as etapas do projeto com a letra da música "O que é que a baiana tem?" e serão apresentados os resultados que podem ser aplicados na própria instituição e em quaisquer outras que tenham alunos surdos. 


\section{Práticas de letramentos visuais}

Com base em Kress e Van Leeuwen (2001), o Letramento Visual é a habilidade de interpretar a informação visualmente apresentada baseando-se na premissa de que imagens podem ser lidas, e que seu significado pode ser decodificado através de um processo de leitura. Habilidades a serem desenvolvidas: observar, identificar detalhes, compreender as relações visuais, pensar e analisar criticamente, criar e comunicar criativamente através de recursos imagéticos.

A partir da percepção dos surdos através da visão, onde sua leitura de mundo se dá basicamente no campo visual, utilizamos elementos da Pedagogia visual para favorecer o aprendizado do aluno surdo.

Apresentamos a foto de Dorival Caymmi para que os alunos conhecessem o compositor, em seguida trabalhamos a sua biografia, a leitura de imagens, utilizamos slides com fotos e vídeos (tradução simultânea) com legenda para ampliar o conhecimento do aluno. A professora fez questionamentos a partir da imagem: Conhecem? Onde nasceu? Qual a profissão? Vale ressaltar que as atividades que aconteceram antes, durante e após a leitura de imagens foram orientadas e mediadas pela professora bilíngue e pelo professor surdo por meio da Língua de Sinais, propiciando ao aluno práticas de leitura em sua própria língua, valorizando a especificidade discursiva da Libras.

Com a observação da obra de arte de Caymmi, Baiana e o casario (1984), os alunos tiveram maior liberdade para construção da narrativa em Língua de Sinais. O objetivo foi despertar o interesse dos alunos pelo, também, pintor, sugerir um nome para o quadro, localizar informações implícitas e explicitas no texto visual, levantar e checar hipóteses.

Observamos a imagem de uma baiana, a indumentária, e realizamos a descrição para trabalharmos posteriormente com o texto escrito $O$ que é que a baiana tem?, partindo ainda da observação da imagem para promover a intertextualidade com a imagem anteriormente apresentada. Utilizamos elementos da indumentária que representa a letra da música para que os alunos pudessem manusear os objetos, conhecer os sinais, as palavras, dinâmicas, utilizando a datilologia (uso do alfabeto manual), construir significados com o texto e vivenciar o texto em movimento. 
Foto 1 - Construção dos conceitos da letra da música “O que é que a baiana tem?” através do concreto

Fonte: arquivo pessoal do autor (2019)

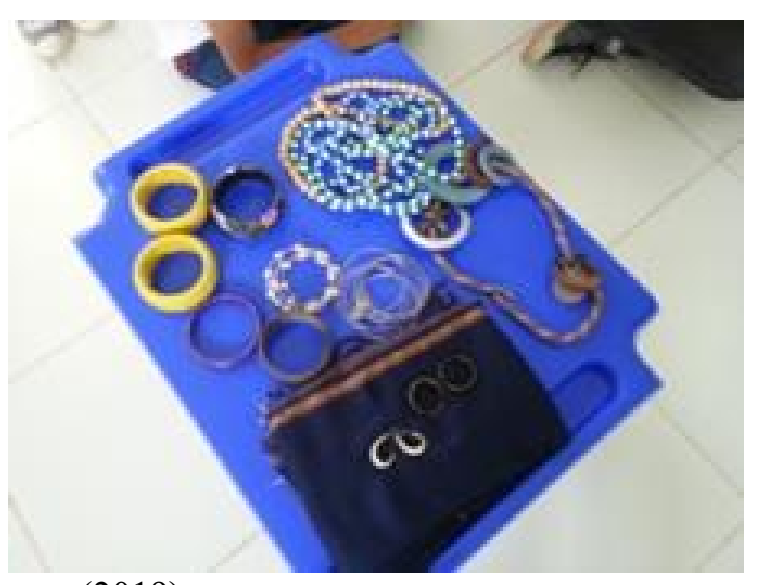

Foto 2 - Construção dos conceitos da letra da música “O que é que a baiana tem?” através do concreto

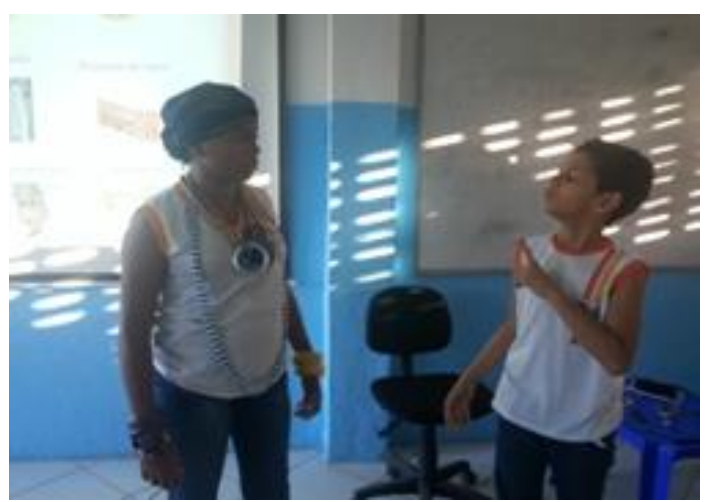

Fonte: arquivo pessoal do autor (2019)

Foto 3 - Construção dos conceitos da letra da música “O que é que a baiana tem?” através do concreto

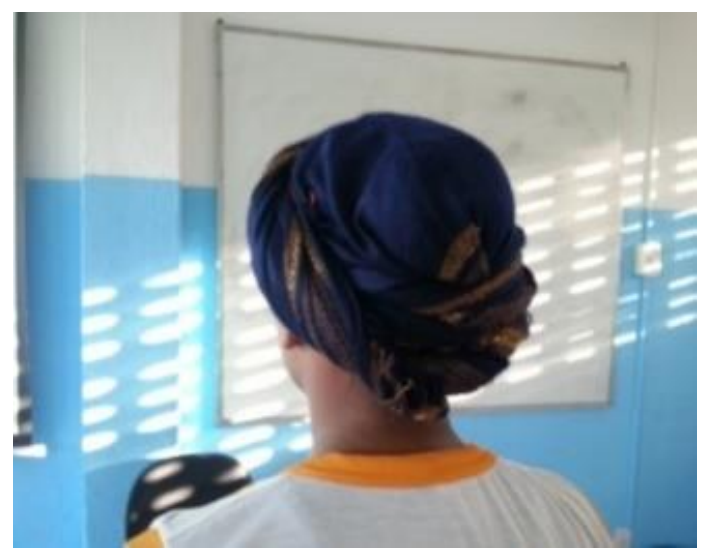

Fonte: arquivo pessoal do autor (2019)

Rev. EntreLínguas, Araraquara, v. 6, n. 2, p. 357-369, jul./dez., 2020. 


\section{Práticas de Letramentos Multimodais para o Ensino do Português como Segunda Língua}

Um dos grandes desafios para os professores dos alunos surdos é ensinar o português na modalidade escrita pensando em metodologias específicas que contemplem as práticas sociais. Desse modo, o uso do português escrito poderá ganhar significado para os alunos surdos e, posteriormente, eles poderão compreender a relevância de sua aprendizagem e a função social da escrita no cotidiano.

Os professores fazem adaptações dos livros didáticos e de textos literários, entre outros, buscando elementos da Pedagogia Visual para favorecer o aprendizado da língua portuguesa na modalidade escrita, mas essas adaptações não são satisfatórias se considerar que, nessas publicações, os surdos não se veem representados. Para que os sujeitos surdos possam se reconhecer como atores sociais, é necessário que sejam contempladas a sua cultura e identidade em diversos contextos. Perlin e Strobel (2006) acrescentam que são narrativas culturais, discursos dos sujeitos ou grupos que estão marcados por práticas culturais que perpassam pela transmissão dos conhecimentos e informações pela língua de sinais, narrativas de identidade nas quais ocorre a subjetivação do sujeito e reconhecimento como sujeitos surdos.

De acordo com Kleiman (2008), o letramento significa uma prática discursiva de determinado grupo social, não envolvem necessariamente as atividades específicas de ler ou de escrever, mas utiliza práticas sociais de leitura e escrita. Como ponto de partida, caberá à escola promover práticas letradas que permitam aos sujeitos surdos a aquisição da Libras como primeira língua e o aprendizado da Língua Portuguesa, como segunda língua. Assim, os surdos se apropriarão de um sistema de escrita por processos da sua experiência visual nas interações com a sociedade.

Partindo desses pressupostos, observou-se a necessidade de apresentar a língua portuguesa de forma funcional, promovendo o desejo de uso em diversos contextos. Dessa forma, foi pensada a construção de um vídeo multimodal para possibilitar a interação do leitor de maneira intensa, promovendo espaço de produção colaborativa de forma a potencializar as interações entre surdos e ouvintes, utilizando as linguagens diversas. Segundo Magalhães, não basta saber "usar" tecnologias, faz-se necessário ter uma postura tecnológica. A partir disto, a cultura tecnológica gradativamente vai se instaurando nas instituições. Com essa proposta de trabalho pretende-se estimular o uso das tecnologias nas escolas inclusivas e bilíngues criando novas possibilidades de expressões e comunicações.

Segundo Lemke (1998), quando possibilitamos aos nossos alunos atividades com textos multimodais e multissemióticos, o conjunto de convenções, já utilizado na produção de sentido 
nos textos escritos, é ampliado e ressignificado, o que explica a multiplicidade de leituras possíveis para os textos multimodais. Entende-se, portanto, que meios construídos para fins da realidade das escolas inclusivas e bilíngues são úteis às práticas pedagógicas, tornando-as mais próximas das manifestações tecnológicas acessíveis aos educandos.

O vídeo multimodal foi produzido para proporcionar um novo ambiente de comunicação e incorporação de práticas letradas, promovendo uma diversidade cultural e de linguagens na escola e fora dela. Desenvolver vídeos com características de hipertextos, interativos em vários níveis linguísticos, permitiu produções colaborativas, ampliou a visão de mundos dos alunos surdos e possibilitou seu uso como recurso pedagógico para os alunos que frequentam o AEE, os alunos surdos das escolas inclusivas e os alunos surdos da própria Associação.

Os alunos assistiram ao vídeo em Libras com a letra da música $O$ que é que a baiana tem? buscando promover a apropriação da língua. Realizaram a leitura e produção textual em libras a partir dos textos apresentados na sua língua e nas gravações dos próprios alunos, em seguida tiveram acesso ao texto biográfico impresso para realizar a leitura em língua portuguesa, propiciando ao aluno uma postura de leitor e a professora um levantamento do conhecimento do léxico (L2) do aluno surdo, leram através das imagens trabalhadas, apresentamos as imagens referentes ao texto solicitando que os mesmos fizessem relação entre as imagens e o texto. Para Fernandes (2006), a ideia fundamental de hipóteses de leitura se realiza pelas pistas imagéticas e textuais. Por isso a importância de o professor relacionar a imagem com o texto escrito para que ganhe significado para o aluno e nele desperte o desejo de ler. Promovemos rodas de leituras usando os procedimentos de antecipação e inferências, no sentido de chamar a atenção dos alunos para que os mesmos explorassem nos textos o máximo de informação, assistimos aos vídeos produzidos pelos alunos fortalecendo as práticas de leitura em Libras.

Com estas atividades os alunos passaram por várias etapas de leitura; leram a palavra representada por meio da imagem e através da Libras, estabeleceram relação entre o sinal e a palavra usando o dicionário online libras (http://www.acessobrasil.org.br/libras) e o aplicativo hand talk como suporte para ampliação dos conhecimentos tanto em libras quanto no português escrito. Usaram o alfabeto manual para fazer a datilologia, associaram a palavra escrita com o alfabeto manual e leram as palavras no texto. Estas etapas de leitura estão descritas no livro Idéias para ensinar português para alunos surdos, de Quadros e Schmiedt (2006). Os alunos construíram significados entre o conhecimento prévio da Língua Portuguesa e o conhecimento veiculado no texto. Pensando na construção do vídeo multimodal a partir desta atividade os alunos reforçaram a internalização do texto escrito. 
O projeto culminou com a apresentação no auditório da AESOS, para todos os alunos da escola, do vídeo multimodal construído pelos alunos com algumas letras das músicas de Dorival Caymmi. Promovemos uma tarde com elementos culturais da Bahia, quando os alunos puderam assistir e participar da roda de capoeira e tivemos a presença da baiana de acarajé. Registramos os momentos através de fotos.

Foto 4 - Tarde com elementos culturais

Fonte: arquivo pessoal do autor (2019)

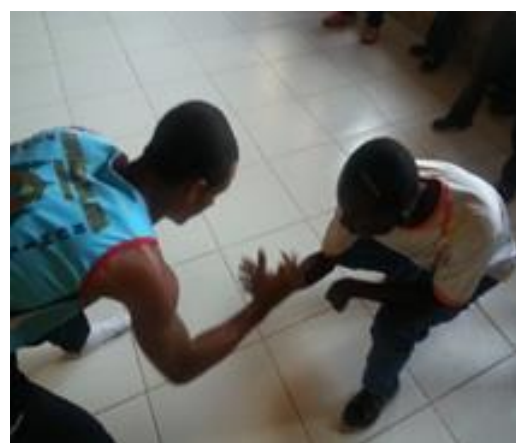

Foto 5 - Tarde com elementos culturais

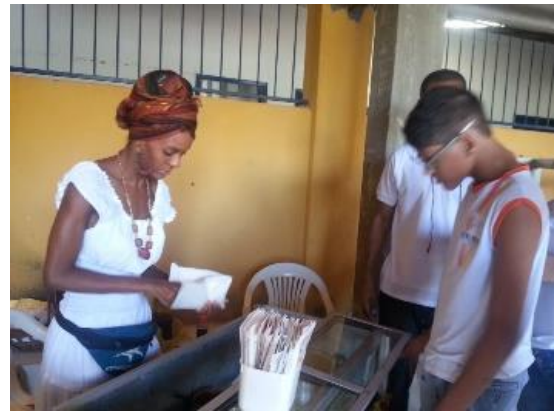

Fonte: arquivo pessoal do autor (2019)

Foto 6 - Tarde com elementos culturais

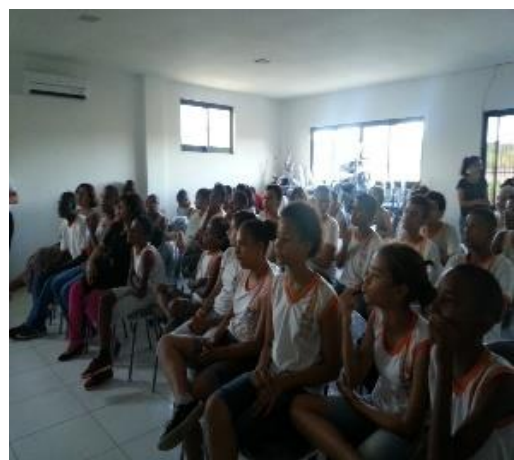

Fonte: arquivo pessoal do autor (2019) 


\section{Resultados e discussões}

Nossa proposta pedagógica aponta uma relevância significativa na educação de surdos, uma vez que os alunos problematizaram, analisaram alguns textos multimodais, leram e produziram textos em Libras e no português escrito, se apropriaram de um sistema de escrita por processos das suas experiências visuais e elaboraram textos novos a partir do texto já existente. Vivenciaram uma dimensão discursiva, construíram conceitos nas duas línguas, estabeleceram diálogos com uma Pedagogia dos Multiletramentos, contribuindo não somente para a construção de recursos didáticos pautado em uma pedagogia bilíngue, mas também com o desenvolvimento de reflexões teóricas acerca dos multiletramentos para pessoas surdas. A construção do vídeo em Libras pelos alunos surdos tornou-se um fator diferencial para o desenvolvimento das práticas de letramentos. Alguns estudos (LODI, 2014; PELUSO, 2007; 2011) sinalizam que textos/discursos produzidos e elaborados em língua de sinais, se gravados em vídeos, podem constituir um instrumento para a perpetuação dos enunciados em língua de sinais, gêneros do discurso, instituídos historicamente, a partir das novas interações verbais dos surdos nas diferentes esferas de atividade.

Bakthin (1992) propõe uma abordagem com foco no meio social, na língua e a nas interações verbais que postulam a dialogia. O texto não é visto isoladamente, correlaciona-se com outros discursos próximos. As práticas de multiletramentos durante o projeto de Dorival Caymmi possibilitou aos alunos e professores uma experiência nas duas línguas em seu uso social. A partir da atuação dos surdos no vídeo multimodal, eles se envolveram em práticas discursivas em contato com seus pares, os textos de Caymmi dialogaram entre si promovendo a intertextualidade e os alunos construíram novos conhecimentos.

Vale ressaltar que as professoras regentes dos $4^{\circ}$ e $5^{\circ}$ anos utilizaram os textos de Caymmi para as avaliações da III unidade, contemplado as outras disciplinas numa proposta interdisciplinar, e os alunos obtiveram um resultado positivo em todas as áreas do conhecimento.

\section{REFERÊNCIAS}

BAKHTIN, M. Os gêneros do discurso. In: Bakhtin, M. Estética da criação verbal. São Paulo: Martins Fontes, 1992.

BEGROW, D.; LIRA, L.; PEREIRA, R. Letramento na educação bilíngue para surdos: a poesia de Cecília Meireles em Libras como facilitadora. In: CONGRESSO INTERNACIONAL, 13.; SEMINÁRIO NACIONAL DO INES, 19., 2014, Rio de Janeiro. Anais [...]. Rio de Janeiro, set. 2014. p. 179-186. 
BRASIL. Ministério da educação. Secretaria de Educação Especial. Lei n. 10.436, de 24 de abril de 2002. Dispõe sobre a Língua Brasileira de Sinais - Libras e dá outras providências. Brasília, 25 abr. 2002. Disponível em:

http://www.planalto.gov.br/ccivil_03/leis/2002/110436.htm. Acesso em: 15 mar. 2020.

BRASIL. Presidência da República. Decreto n. 5.626, de 22 de dezembro de 2005. Regulamenta a Lei n. 10.436, de 24 de abril de 2002, que dispõe sobre a Língua Brasileira de Sinais - Libras, e o art. 18 da Lei n. 10.098, de 19 de dezembro de 2000. Brasília, 23 dez. 2015. Disponível em: http://www.planalto.gov.br/ccivil_03/_ato2004-2006/2005/decreto/d5626.htm. Acesso em: 15 mar. 2020.

FERNANDES, S. F. Práticas de letramento na educação bilíngue para surdos. Curitiba: SEED, 2006.

FOUCAULT, M. Microfísica do poder. Organização e tradução de Roberto Machado. Rio de Janeiro: Editora Graal, 2010.

GESSER, A. LIBRAS? Que língua é essa? Crenças e preconceitos em torno da língua de sinais e da realidade surda. São Paulo: Parábola Editorial, 2009.

KARNOPP, L.; PEREIRA, M. C. Concepções de leitura e de escrita e educação de surdos Leitura e escrita no contexto da diversidade. Porto Alegre: Editora Mediação, 2004. p. 33-38.

KRESS, G.; VAN LEEUWEN, T. Multimodal discourse. The modes and media of contemporary communication. London: Hodder Arnold, 2001.

LACERDA, C. A prática pedagógica mediada (também) pela língua de sinais: trabalhando com sujeitos surdos. Cadernos CEDES, Campinas, v. 20, n. 50, p. 70-83, 2000.

LEMKE, J. Multiplying meaning: visual and verbal semiotics in scientific text. In: MARTIN, J. R.; VEEL, R. (Eds.). Reading Science. Routledge, 1998. Disponível em:

http://www.jaylemke.com/storage/MultiplyingMeaning1998.pdf. Acesso em: 10 out. 2014.

LODI, A. C. A leitura como espaço discursivo de construção de sentidos: o de sentidos oficinas com surdos. Orientadora: Roxane Helena Rodrigues Rojo. 2004. 282 f. Tese (Doutorado em Linguística Aplicada e Estudos da Linguagem) - Pontifícia Universidade Católica, São Paulo, 2004. Disponível em: http://www.leffa.pro.br/tela4/Textos/Textos/Teses/ana_claudia_lodi.pdf. Acesso em: 15 mar. 2020.

MAGALHÃES, A. R.; PAIVA, V. S. Limites, possibilidades e potencialidades das redes de apoio a implantação da cultura das TIC em curso de formação de professores. Disponível em: http://ticeduca.ie.ul.pt/atas/pdf/319.pdf. Acesso em: 10 out. 2014.

PELUSO, L. Estudios interculturales y cultura escrita: algunas problematizaciones em torno al concepto de escritura y de sujeto letrado. In: Edición de la Sociedad de Dislexia del Uruguay (org.). Entre el sueño y la realidad: nuestra América Latina alfabetizada. Montevideo, 2007. p. 313-320.

PERLIN, G.; STROBEL, K. Fundamentos da educação de surdos. Florianópolis: UFSC, 2006. 
PINHEIRO, V. Aspectos da Pedagogia Visual. In: CONGRESSO INTERNACIONAL, 8.;

SEMINÁRIO NACIONAL DO INES, 14., Rio de Janeiro. Anais [...]. Rio de Janeiro, 2009. p. 115122.

QUADROS, R. de; SCHIEDT, M. Idéias para ensinar português para alunos surdos. Brasília: MEC, 2006.

QUADROS, R. de. Educação de surdo: a aquisição da linguagem. Porto Alegre: Artes Médicas, 1997.

ROJO, R. Letramentos múltiplos, escola e inclusão social. São Paulo: Parábola Editorial, 2009.

ROJO, R.; MOURA, E. (orgs.). Multiletramentos na escola. São Paulo: Parábola editorial, 2012.

SILVA, M. A construção de sentidos na escrita do aluno surdo. São Paulo: Plexus, 2001.

SOARES. Magda. Linguagem e escola uma perspectiva social. 17. ed. São Paulo: série fundamentos, 2008.

\section{Como referenciar este artigo}

MACEDO, Y. M. Letramentos multimodais para o ensino do português como segunda língua para surdos. Rev. EntreLínguas, Araraquara, v. 6, n. 2, p. 357-369, jul./dez., 2020. e-ISSN: 2447-3529. DOI: https://doi.org/10.29051/el.v6i2.13805

Submetido em: 10/03/2020

Revisões requeridas: 26/04/2020

Aprovado em: 01/06/2020

Publicado em: 30/09/2020 